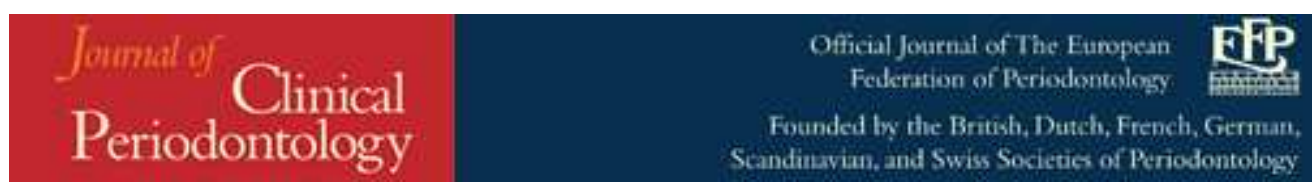

\title{
Diabetes mellitus negatively affects peri-implant bone formation in the diabetic domestic pig
}

\begin{tabular}{|c|c|}
\hline Journal: & Journal of Clinical Periodontology \\
\hline Manuscript ID: & CPE-09-10-2852.R4 \\
\hline Manuscript Type: & Original Article Implant Dentistry \\
\hline $\begin{array}{r}\text { Date Submitted by the } \\
\text { Author: }\end{array}$ & 10-May-2011 \\
\hline Complete List of Authors: & $\begin{array}{l}\text { von Wilmowsky, Cornelius; University of Erlangen, Department of } \\
\text { Maxillofacial Surgery } \\
\text { Stockmann, Philipp; University of Erlangen, Department of } \\
\text { Maxillofacial Surgery } \\
\text { Harsch, Igor; University of Erlangen, Department of Medicine I } \\
\text { (Endocrinology and Metabolism) } \\
\text { Amann, Kerstin; University of Erlangen, Department of Pathology } \\
\text { Metzler, Philipp; Universitätsspital Zürich, Department of } \\
\text { Maxillofacial Surgery } \\
\text { Lutz, Rainer; University of Erlangen, Department of Maxillofacial } \\
\text { Surgery } \\
\text { Moest, Tobias; University of Erlangen, Department of Maxillofacial } \\
\text { Surgery } \\
\text { Neukam, Friedrich; University of Erlangen, Department of } \\
\text { Maxillofacial Surgery } \\
\text { Schlegel, Karl; University of Erlangen, Department of Maxillofacial } \\
\text { Surgery }\end{array}$ \\
\hline Topic: & Implantology \\
\hline Keywords: & Immunohistochemistry, Periodontal disease \\
\hline Main Methodology: & Animal Model \\
\hline
\end{tabular}

\section{SCHOLARONE \\ Manuscripts}




\section{Diabetes mellitus negatively affects peri-implant bone formation in the diabetic domestic pig}

Cornelius von Wilmowsky ${ }^{1 *}$, Philipp Stockmann ${ }^{1}$, Igor Harsch ${ }^{2}$, Kerstin Amann ${ }^{3}$, Philipp Metzler ${ }^{1}$, Rainer Lutz ${ }^{1}$, Tobias Moest ${ }^{1}$, Friedrich Wilhelm Neukam ${ }^{1}$, Karl Andreas Schlegel ${ }^{1}$

\footnotetext{
${ }^{1}$ University of Erlangen-Nuremberg, Department of Oral and Maxillofacial Surgery, Glueckstrasse 11, 91054 Erlangen, Germany

${ }^{2}$ University of Erlangen- Nuremberg, Department of Medicine I (Endocrinology and Metabolism), Ulmenweg 18, 91054 Erlangen, Germany

${ }^{3}$ University of Erlangen- Nuremberg, Department of Pathology, Krankenhausstrasse 8-10, 91054 Erlangen, Germany
}

Running title: Peri-implant bone formation in diabetes

Keywords: Diabetes; Bone; Implants; Osseointegration; Pig

*corresponding author; e-mail: c.wilmowsky@web.de

Tel: ++49-9131-8535800; Fax: ++49-9131-8534219

"The authors declare that they have no conflict of interests" 


\begin{abstract}
Aim: Diabetes mellitus is classified as a relative contraindication for implant treatment, and higher failure rates have been seen in diabetic patients. The aim of the present study was to investigate the effect of diabetes on peri-implant bone formation in an animal model of human bone repair.

Materials and Methods: Diabetes was induced by intravenous application of streptozotocin $(90 \mathrm{mg} / \mathrm{kg})$ in 15 domestic pigs. Implants were placed after significant histopathological changes in the hard and soft tissues were verified. The bone-implant-contact (BIC), peri-implant bone mineral density (BMD), and expression of collagen type-I and osteocalcin proteins were qualitatively evaluated 4 and 12 weeks after implantation. Fifteen animals served as healthy controls.

Results: Diabetes caused pathological changes in the soft and hard tissues. The BIC and BMD were significantly reduced in the diabetic group after 4 and 12 weeks. Collagen type-I was increased in the diabetic group at both time points, whereas osteocalcin was reduced in the diabetic group.

Conclusions: Poorly controlled diabetes negatively affects peri-implant bone formation and bone mineralization. These findings have to be taken into consideration for diabetic patients with an indication for implant therapy.
\end{abstract}




\section{Clinical Relevance}

Scientific rationale for the study: The number of diabetic patients worldwide is expected to increase to 366 million by the year 2030. We investigated peri-implant bone formation in a diabetic animal model of human bone repair.

Principal findings: We found that histopathological changes in the hard and soft tissue due to diabetes mellitus negatively affect peri-implant bone formation, mineralization, and the expression of bone matrix proteins.

Practical implications: These findings have to be taken into consideration in the clinical setting with patients who have poorly controlled diabetes and an indication for dental implants. 


\section{Introduction}

Diabetes mellitus is one of the most prevalent endocrine diseases and the third most common cause of disability and morbidity in the western world. In the year 2000, more than 171 million people were suffering from diabetes, and the number of diabetics has been predicted to increase to 366 million worldwide by the year 2030 (Wild et al. 2004). Thus, the number of diabetic patients indicated for dental implants will grow steadily.

Diabetes is associated with an increased prevalence and extent of periodontitis and tooth loss compared to non-diabetic patients (Ferreira et al. 2006, Kaur et al. 2009). A direct correlation has been shown between alterations in implant stability and impaired implant integration and hyperglycaemic conditions (Oates et al. 2009). Diabetes mellitus is classified as a risk factor for implant treatment, and severe or poorly controlled diabetes mellitus has been suggested to be a contraindication for treatment with dental implants (Buser et al. 2000, Neukam \& Esser 2000). On the other hand, Tawil et al. (2008) found that individuals with well controlled diabetes have implant survival rates similar to those of controls without diabetes.

Even though several clinical studies have analysed the success and failure of implants in diabetic patients, only experimental animal studies allow a systematic evaluation of the biological and pathological effects of diabetes on the osseointegration of implants and medical devices (MelladoValero et al. 2007, Oates et al. 2009). In an experimental study in diabetic rabbits, Margonar et al. (2003) reported that diabetes mellitus negatively influences the mechanical retention of implants placed in the tibia, regardless of whether insulin therapy was applied. Giglio et al. (2000) investigated the osseointegration of dental implants placed in the tibiae of diabetic rats; newly formed bone around implants was immature and less organized in uncontrolled diabetic rats compared to non-diabetic controls. Another study reported a bone-implant-contact of less than $50 \%$ in alloxan-induced diabetic rats compared to healthy controls (Siqueira et al. 2003). However, Gerritsen et al. (2000) demonstrated that diabetes mellitus has no adverse effect on the clinical performance of percutaneous implants in rabbits, claiming that impaired wound healing in diabetes is not a contraindication for the anchorage of percutaneous implants in cortical bone. Thus, clinical trials and experimental animal studies evaluating the effect of diabetes on implant failure are still controversial. Furthermore, the coherence between diabetes and wound healing is complex and not yet fully understood, particularly in regards to the oral cavity (Taylor et al. 2004). 


\section{Materials and Methods}

\section{Animals and surgical procedure}

Twenty-five domestic pigs (10 healthy controls and 15 diabetic) were used in this study. Housing and feeding were according to standard animal care protocols. The animals were under sequential veterinary control during the entire experimental period. The experimental protocol was approved by the Committee for Animal Research, Government of Midfranconia, Ansbach, Germany (Approval No. 54-2531-25/07). All surgical procedures and the induction of diabetes were performed using intubation anaesthesia. Streptomycin ( $0.5 \mathrm{~g} /$ day; Gruenenthal, Stolberg, Germany) was applied intramuscularly 1 $\mathrm{h}$ before the operation and 2 days postoperatively. For postoperative pain control, each animal received buprenorphin every $12 \mathrm{~h}$ for 3 days at a dose of $0.1 \mathrm{mg} / \mathrm{kg}$ body weight (BW).

\section{Induction of diabetes mellitus}

The animals were 12 weeks old $(33 \pm 3.4 \mathrm{~kg})$ at the beginning of the study. For the induction of diabetes, streptozotocin (STZ) (90 mg/kg BW, Zanosar, Pharmacia, Pfizer, New York, USA) was 
dissolved in saline $(1 \mathrm{~g} / 10 \mathrm{ml})$ and administered to the pigs intravenously via an ear vein with continuous infusion over 15 minutes.

In order to define diabetes and meet the criteria set by the World Health Organisation (WHO) and American Diabetes Association (ADA) for diabetes, the blood glucose level and BW were measured on a regular basis and an intravenous glucose tolerance test (IVGTT) carried out as described previously (WHO 2006, ADA 2010, von Wilmowsky et al. 2010) (Table 1).

\section{Implant surgery}

The implants were placed after 15 months after the induction of diabetes (Fig. 1). This time frame was chosen to guarantee that the diabetes was present long enough to induce significant pathological changes in the hard and soft tissues. Thus, we aimed to guarantee that the implants were placed in a compromised wound healing situation.

Two test groups were formed and examined at two different time points. Five healthy controls and eight diabetic animals were examined 4 weeks after implant placement (16 months after the induction of diabetes), and the other five healthy and seven diabetic animals were examined at 12 weeks (18 months after the induction of diabetes). Five implants (Straumann SLA, $4.1 \mathrm{~mm}$ diameter, $10 \mathrm{~mm}$ length; Straumann $\mathrm{GmbH}$, Freiburg, Germany) were placed in the frontal skull of each animal. A sagittal incision was made, the soft tissue and periosteum mobilised, and the implants inserted into the bone. The periosteum and skin were closed over the defects using absorbable Vicryl sutures (Vicryl® 3.0; Vicryl® 1.0; Ethicon GmbH \& Co. KG, Norderstedt, Germany).

To evaluate diabetes-induced histopathological changes in the hard and soft tissues, biopsies were taken from the left ear and frontal skull before the induction of diabetes, and 6 and 12 months after the administration of STZ. The biopsies were evaluated quantitatively and qualitatively using microradiography, light microscopy, and scanning electronic microscopy as described previously (von Wilmowsky et al. 2010). Biopsies were also taken after the scarification of the animals at 16 and 18 months to measure the bone mineral density $(B M D)$ and further analyse the hard and soft tissue qualitatively (Fig. 1).

\section{Histological preparation}

In order to obtain the samples for histology, the animals were sacrificed 4 and 12 weeks after implant insertion. The animals were given an intramuscular injection of azaperone $(1 \mathrm{mg} / \mathrm{kg})$ and midazolam (1 
$\mathrm{mg} / \mathrm{kg}$ ) in the neck, and then euthanized by an intravascular injection of $20 \%$ pentobarbital solution until cardiac arrest occurred. The skull cap was removed and immediately frozen at $-80^{\circ} \mathrm{C}$. Samples were immersed in $1.4 \%$ paraformaldehyde at $4^{\circ} \mathrm{C}$ in order to remove insoluble organic matrix constituents. The samples were subsequently dehydrated in an ascending alcohol series at room temperature in a dehydration unit (Shandon Citadel 1000, Shandon GmbH, Frankfurt, Germany). The explants were embedded using Technovit 9100 (Heraeus Kulzer, Kulzer Division, Werheim, Germany), which is suitable for the cutting and grinding technique suggested by Donath and Breuner (1982). To produce microradiographs, the embedded bone specimens were reduced to $120-\mu \mathrm{m}$ sections using a precision saw and grinding machine (Exakt Gerätebau, Norderstedt, Germany) (Fig. 2a). The bone specimens were reduced to $30 \mu \mathrm{m}$ to apply toluidine blue $\mathrm{O}$ solution for the evaluation of boneimplant-contact (BIC). The samples were polished and treated in a continuously stirred $10 \% \mathrm{H}_{2} \mathrm{O}_{2}$ solution for $5 \mathrm{~min}$. The polished sampled were rinsed with water, dried, and stained in toluidine blue $\mathrm{O}$ solution for $15 \mathrm{~min}$. The harvested soft tissue biopsies were qualitatively assessed for angiopathies by the evaluation of irregularities in the endothelium and examined with a scanning electron microscope (SEM; Fig. 2b) (FE-SEM, S-4800, Hitachi, Japan).

To qualitatively evaluate the bone samples, they were fixed in formalin, decalcified, embedded in paraffin, and stained using the Masson Goldner Trichrome (MG) dying method. Examination of the slides consisted of descriptive histology using light and polarization microscopy analysis (Axioskop, Zeiss, Oberkochen, Germany; 20x magnification, Fig. 3) (Saino et al. 2003).

\section{Microradiography and bone mineral density}

To produce microradiographs, the resin-embedded bone sections were irradiated in a cabinet X-ray system (Faxitron X-ray, Lincolnshire, USA) using a tube voltage of $13 \mathrm{kV}$ and $0.3 \mathrm{~mA}$ for $2.5 \mathrm{~min}$. The developed radiographs (Kodak, Stuttgart, Germany) were scanned into tiff format (Epson perfection 4990 Photo, Seiko Epson Corp, Nagano, Japan). The mineral density was measured from the microradiograph as described previously (Boivin \& Meunier 2002) using Bioquant Osteo software V7.10.10 (Bioquant, Nashville, USA) to analyse the samples at four different spots (two on each side; 10x magnification; Fig. 2a). The percentage of colour scaling on a grey scale image can be determined with this program. The area where mineralized tissue was detected and calculated as a percentage of the total area was determined to be the mineral density. 


\section{Bone-implant-contact}

Stained specimens were examined at four spots (two on each side of the implant; Fig. 2b) under a light microscope (Axio Imager A1, Zeiss, Jena, Germany; 10x magnification) and subsequently fed into a computer with an attached video camera (QICAM FAST 1394, Qimaging, Canada). Bioquant Osteo software V7.10.10 was used to determine the percentage of direct contact between mineralized bone and the implant surface, the BIC.

\section{Immunohistochemistry}

For immunohistochemical analysis, the samples were cut in $5-\mu$ m-thick slices using a microtome saw (Leica, Wetzlar, Germany) and dyed using antibodies for collagen type-I (Novocastra, Berlin, Germany) and osteocalcin (Takara Biomedicals Europe, Saint Beauzire, France) (Fig. 2c). Histological sections were partly pre-treated in citrate buffer for collagen type-I staining. Endogenous peroxidase was blocked by incubation in $3 \% \mathrm{H}_{2} \mathrm{O}_{2}$ solution for $15 \mathrm{~min}$. The surface of the sample was subsequently blocked with protein-block serum free (Dako Diagnostics $\mathrm{GmbH}$, Berlin, Germany) to prevent nonspecific staining. Next, the primary antibodies against collagen type-I (1:10) and osteocalcin (1:1500) were added. To enable a coloured presentation, secondary antibody (Dako Diagnostics) was added. Finally, the addition of StreptAB/HRP (Dako Diagnostics) enabled the binding of the actual dye, AEC1 (Dako Diagnostics). The procedure was completed by haematoxylin-eosin counterstaining. All samples were accompanied by a negative control. Immunohistochemical analysis was performed at four different regions of interest (ROI) with 20 -fold magnification (Fig. 2c). Stained areas of the ROI were digitally marked, and the percentage of stained area determined using the Bioquant Osteo software V7.10.10.

\section{Statistical analysis}

All measurements were performed by one examiner who was blinded to the identity of the specimens being evaluated. All values are given as means and standard deviation. The software program SPSS (version 14.0 for Windows) was used to analyse all data. Differences among groups and days were evaluated by the Mann-Whitney U-test. Multiple testing has not been performed due to a comparison of only two groups: control vs. diabetic. Values of $p<0.05$ were considered significant. 


\section{Qualitative evaluation of the hard and soft tissues}

After 18 months, SEM examination of the vasculature of the ear lobe skin in the healthy pigs $(n=5$ samples) revealed regularly shaped endothelial cells with no signs of increased size or disconnection. The endothelium was smooth and in regular condition (Fig. 4a and b). In contrast, examination of the skin of the diabetic group ( $\mathrm{n}=7$ samples) showed mixed parietal microthrombi consisting of platelets and fibrin on the vascular endothelium. The endothelium usually showed changes in the form of an irregular, fissured surface and detachment of endothelial cells. (Fig. $4 \mathrm{c}$ and d).

Qualitative evaluation of the hard tissue biopsies of the control animals ( $n=5$ samples) found regularly shaped bone after 18 months. The MG staining revealed inconspicuous signs of bone remodelling that seemed to be physiological (Fig. 3a). Polarisation microscopy of the same samples showed physiological mineralization areas (Fig. 3b). In contrast, the bone samples from the diabetic group $(n=$ 7 samples) were irregularly shaped and showed wider bone trabeculae with a compressed bone marrow space (Fig. 3c). The mineralization zones were expanded compared to the healthy control group, which was verified by polarisation microscopy (Fig. 3d).

Even though the degree of distinctiveness of the microangiopathie and bone morphology showed variances within the animals of the diabetic group, pathological differences were apparent in all animals compared to the samples of the healthy control animals.

\section{Bone mineral density}

The BMD results are given in Table 2. Examination of the peri-implant BMD 4 weeks after implant placement revealed significantly greater bone mineralization in the healthy control group $(n=25$ implants) compared to the diabetic group ( $n=40$ implants; Fig. 5). Twelve weeks after implant placement, a significantly higher peri-implant BMD was measured in the control group ( $n=25$ implants) compared to the diabetic group ( $n=35$ implants; Fig. 5$)$.

Regarding time differences no significance could be found between 4 and 12 weeks, neither in the control group $(p=0.981)$ nor in the diabetic group $(p=0.246)$. 


\section{Bone-implant-contact}

The results of the evaluation of bone in direct contact with the implants are given in Table 2. Four weeks after implant placement, BIC was significantly increased in the control group ( $n=25$ implants) compared to the diabetic group ( $n=40$ implants; Fig. 5). Twelve weeks after implant placement, BIC decreased in both groups ( $n=25$ implants in control vs. $n=35$ implants in diabetics), and the difference remained significant (Fig. 5).

The comparison of both points in time showed no significant difference in the control group $(p=0.876)$ and in the diabetic group $(p=0.397)$.

\section{Immunohistochemistry}

The protein expression measured for collagen type-1 and osteocalcin as a percentage of stained area is given in Table 2. Collagen type-I expression was lower in the control group ( $n=25$ implants) compared to the diabetic group ( $n=40$ implants) at 4 weeks, but the difference was not significant (Fig. 6). Twelve weeks after implant placement, collagen type-l expression decreased in both group $(n=25$ implants in control vs. $\mathrm{n}=35$ implants for diabetic), and the difference remained non-significant (Fig. 6). Between 4 and 12 weeks no significance could be found in the protein expression in the control group $(p=0.341)$. The protein expression in the diabetic group did significantly decrease after 4 weeks $(p=0.022)$.

Osteocalcin expression at 4 weeks was lower in the diabetic group ( $n=40$ implants) compared to the control group ( $n=25$ implants), but the difference was not significant (Fig. 6). After 12 weeks, the expression of osteocalcin increased in both groups $(n=35$ implants in diabetic group vs. $n=25$ implants in the control), and the difference remained non-significant (Fig. 6). The increase of protein expression was significantly higher in both groups between 4 and 12 weeks (control $p=0.015$; diabetic $p=0.045$ ).

\section{Discussion}

Compared with the general population, a higher implant failure rate is seen in diabetic patients. Therefore, diabetes is currently classified as a relative contraindication for implant therapy (Morris et al. 2000). Animal models are essential for understanding of biological pathways and regulation leading to diminished osseointegration, and thus understanding the mechanisms leading to increased implant 
loss. A certain transferability of the results to humans might be possible if the animal model is chosen carefully for the aspects and questions being investigated (Held 1983).

Even though many experimental studies have been performed with diabetic animals, they have dealt with two fundamental problems: the choice of the animal model and the time point chosen for the placement of implants. Regarding the animal model, the selection of an appropriate experimental model with bone repair analogous to that of humans is a prerequisite for the transferability of the experimental results to clinical applications (Bosetti et al. 2003).

Although the rat is one of the most commonly used species in diabetes and medical research, it has notable dissimilarities with humans regarding bone micro- and macrostructure, as well as bone composition. Furthermore, the limitations of size make rats unsuitable for testing multiple implants simultaneously (Pearce et al. 2007). Studies dealing with rabbits face the same problems. The rabbit reaches skeletal maturity at around 6 months of age, and the architecture and composition of its bone is remarkably different from that of humans (Gilsanz et al. 1988). However, rabbits are useful and necessary for screening implant materials prior to testing in larger animal models (Pearce et al. 2007). In addition, rats and rabbits have very permissive bone healing and a higher metabolism rate with faster skeletal changes and bone turnover than humans, making their results difficult to evaluate and apply to humans (Nunamaker 1998, Pearce et al. 2007).

With regard to bone anatomy, morphology, healing, and remodelling, the adult domestic pig was our animal of choice. Tissue blood circulation, circulatory processes, fracture healing, and the rate of new bone formation in the pig correlate with those of humans (Borden et al. 2003, Schlegel et al. 2009).

Thus, we previously established a streptozotocin-induced diabetic domestic pig model to evaluate bone formation around dental implants (von Wilmowsky et al. 2010). To ensure that the internal clinical parameters of diabetes mellitus were fulfilled prior to implantation, the soft and hard tissues were systematically evaluated over a 12-month period for pathological changes. The clinical parameters (blood glucose level, BW, IvGTT), determined by the ADA (2010) and WHO (2006) for the definition of diabetes mellitus were fulfilled. Pathological changes were already visible in the skin vasculature after 6 months, with significant arterial wall thickening in the diabetic group which is in accordance with the literature (Marshall et al. 1980). The BMD was lower in the diabetic group after 6 months, with a significant difference compared to control pigs after 12 months (von Wilmowsky et al. 2010). After validating these pathological changes, the implants were inserted. 
Thus, we had a pathological situation that is often found in diabetic patients, as $50 \%$ of type 1 diabetes patients have significant histopathological changes in the bone macrostructure compared to healthy age-matched subjects, and almost $20 \%$ of patients aged 20 - 56 years meet the criteria for osteoporosis. Therefore, a large proportion of diabetic patients with an indication for implant therapy are suffering from diminished bone quality (McCabe 2007, Adami 2009).

Animal studies lasting for only a short time period might not resemble the compromised bone healing seen clinically in humans. As we found, it takes 12 months to develop significant pathological changes in the hard tissue (von Wilmowsky et al. 2010).

The evaluation of BIC in our study revealed significantly less BIC in the diabetic group compared to the healthy control animals after 15 and 18 months. Other experimental diabetic animal studies have shown that newly formed bone around implants is immature and less organized in diabetic animals compared to healthy control animals, suggesting qualitative differences in the newly formed bone (Nevins et al. 1998). In addition, bone healing around implants after 30 days was delayed in diabetic animals compared to healthy controls (Giglio et al. 2000).

Diabetes seems to have a substantial effect on successful implant osseointegration. Diabetes has been shown to negatively affect bone formation, as well as bone mineralization and bone density (Devlin et al. 1996, He et al. 2004, Goodmann \& Hori 1984). Prerequisite and crucial for proper and regular bone healing and bone mineralization is early vascularisation (Burhardt et al. 1987, Glowacki 1998). Angiopathies are the most frequent secondary complication in diabetes, and the microcirculation is decreased (Martin et al. 2003). Thus, impaired wound healing and wound infections are the main complications of the metabolic context of diabetes (Hirsch et al. 2008). Therefore, we systematically investigated the development of angiopathies in the diabetic domestic pig. SEM evaluation of the skin vasculature 18 months after the induction of diabetes revealed pathological changes visible as altered, swollen, and thickened endothelium with mixed parietal microthrombi, and changes were already visible after 6 months. These angiopathies most likely contribute to endothelial dysfunction and diminished microcirculation, leading to impaired peri-implant bone formation as documented in our study. Thereby advanced glycolation endproducts (AGEs) seem to play a major role in the development of angiopathies among people with diabetes. A constant hyperglycaemia, as it was present in our animals, leads to an increase of AGEs contributing to vascular complications (Ahmed \& Thornalley 2007, Jakus \& Rietbrock 2004). It has been shown that the pharmacological inhibitors that inhibit the formation of AGEs retard the development of vascular complications in 
diabetes (Schalkwijk \& Miyata 2010). Furtermore the formation of AGEs in high glycaemic conditions, such as diabetes, contribute to a slower rate of osseointegration by influencing the expression of bone matrix proteins and thus negatively affect implant stability (Quintero et al. 2010, Retzepi \& Donos 2010).

The hyperglycaemia present in diabetic animals may also contribute to less BIC and lower BMD in our study. Diabetes-related hyperglycaemia can modulate osteoblast signalling pathways and suppress the expression of genes associated with osteoblast maturation. This context leads to decreased calcium uptake in osteoblasts, contributing to less bone mineralization, which was seen in our study (Balint et al. 2001, Zayzafoon et al. 2000). Qualitative and quantitative evaluations of the hard tissue showed less mineralized bone and unorganized bone with diminished quality in the diabetic animals compared to the healthy controls.

Increased glucose metabolism has been suggested to lead to an altered energy status and increased lactate acid synthesis. Acid-sensitive channels expressed on osteoblasts respond to low $\mathrm{pH}$ conditions by decreasing mineralization and gene expression (Jahr et al. 2005, Brandao-Burch et al. 2005). These findings might explain why, in studies with insulin-treated animals, insulin has the capacity to regulate and reduce the effects of diabetes on bone healing, and why no difference was found in the BIC between healthy control and insulin-treated diabetic animals (Siqueira et al. 2003, Kwon et al. 2005). These findings might also explain those of clinical studies investigating the effects of sufficiently controlled diabetes on the osseointegration of dental implants. In a review by Javed and Romanos (2009), no evidence was reported for diminished clinical success or significant early healing complications associated with implant therapy based on the glycaemic control levels in diabetic patients. Therefore, implant placement is not contraindicated in diabetic patients with good metabolic control (Mombelli \& Cionca 2006).

Regarding time effects we could not find any significant differences in both groups between 4 and 12 weeks, neither in the BIC nor in the BMD. A possible explanation for this finding could be the fact, that the implants were placed in spongious bone. It is known that this bone structure has a faster healing time and remodelling in comparison to cortical bone structure (Davies 2003). It can be suggested that the majority of the healing process had already taken place during the first 30 days. On the other hand other studies have shown differences of the amount of BIC during the observation period of 12 weeks. Several factors are influencing the BIC like implant design and surface, insertion technique as well as an immediate or delayed loading of implants. Furthermore the differences in bone architecture of 
different study models might be a parameter influencing bone formation around implants. As stated above the pig was our animal of choice even tough it has been found out that the bone macrostructure of pigs does have a denser trabecular network compared to humans (Mosekilde et al. 1993). Still a missing difference between the BIC after 4 and 12 weeks remains unclear.

A deficit in the recruitment of mesenchymal stem cells (MSCs) of the osteoblastic lineage might contribute to the impaired osteoid matrix production and suppressed osteoblast cell activity observed during the early osseous healing period in diabetes (McCabe 2007). Diabetic animals have been reported to produce sufficient amounts of immature mesenchymal tissue, but they fail to adequately express genes that regulate osteoblast differentiation (Lu et al. 2003). This finding suggests that a difference in the expression of these markers has to be present in the peri-implant bone in both groups because BMD and BIC were significantly reduced in the diabetic group in our study.

Higher levels of collagen type-I were observed in the diabetic group after 4 and 12 weeks. This finding can be explained by the reduced bone mineralization in the diabetic animals. In diabetes, the bone is not adequately mineralized, leaving a greater amount of collagenous, non-mineralized area on bone biopsies. The zones of insufficient mineralized bone were expanded compared to the mineralization zones of the healthy controls. The decreased collagen protein expression between 4 and 12 weeks is feasible as it is considered to be a basic initial bone matrix protein in bone formation, and its expression is an early indicator of de novo bone formation. Furthermore it might be possible that a higher collagen type-I expression could also influence bone density. This has to be quantitatively evaluated in further studies.

In order to gain further information about the process of bone mineralization, we investigated the expression of osteocalcin. The appearance of osteocalcin in bone maturation is known to be delayed from the appearance of collagen type-I, and it indicates the mineralization process in bone formation implemented by the calcification of osteocytes (Thorwarth et al. 2005).

Osteocalcin was diminished in the diabetic group compared to healthy controls after 4 and 12 weeks. Because osteocalcin acts as a calcium binder, diminished expression might contribute to a reduced mineralization potential and rate in the diabetic bone, as that seen in our study (Liebermann et al. 2002). These findings correlate with findings in diabetic patients. Higher serum-osteocalcin levels have been shown to correlate with increased bone mineral density (Kanazawa et al. 2009). Furthermore, decreased osteocalcin mRNA in diabetic bone is assumed to lead to a decreased rate of mineral apposition due to inhibited calcium uptake (Balint et al. 2001, Verhaege et al. 1990, McCabe 2007, 


\section{1}

2

Botolin et al. 2005). Thus, reduced osteocalcin expression reduces the possibility of binding calcium and incorporating it into the matrix, which is necessary for adequate bone matrix mineralization. The statistically significant increase between 4 and 12 weeks might be explained by its delayed appearance in bone formation.

A drawback of the immunohistochemical analysis is the investigation of only two bone matrix proteins at two points of time. Regarding the complexity of the biological pathways of bone metabolism, we are only able to get a picture at a given instant. Lu and colleagues found differences in the expression of osteocalcin and collagen type-I in diabetic mice compared to healthy control animals on day 4 and 6 after marrow ablation (Lu et al. 2003). Earlier time frames for investigation might be necessary to find significant differences in the protein expression pattern. On the other hand it might be suggested that osteocalcin and collagen type-I are important proteins in bone metabolism but do not play a significant role in a pathological, hyperglycaemic situation. Comparisons with human studies regarding the expression of osteoclacin and collagen type-I in a hyperglycaemic situation are not possible since these proteins were mainly evaluated in the serum.

However, the regulation of proteins in the hard and soft tissues of diabetic organisms and the causes of pathological changes in the interaction between molecular pathways remains complex and not fully understood. Even though the results of our immunohistochemical analysis were not significant and the missing statistical differences remain unclear, we believe that these results might be of interest. These findings might be a hint about differences in protein expression and may point to additional parameters that will be important for investigations into the effect of diabetes on peri-implant bone formation.

Even though the diabetic domestic pig is well suited for these kinds of investigations, this animal model and this study have limitations. Due to its size and excessive final body weight, keeping pigs is sometimes intricate and long lasting studies are expensive. Moreover, the implants were placed in the frontal skull. Previous studies have shown that the mineralization rate is not significantly different between the frontal skull of the domestic pig and the maxillary bone of humans (Schlegel et al. 2009), but this fact has not been validated for the bone structure of the lower jaw. Therefore, the results of this study are valid for spongious bone as it can be found in the upper jaw of humans. In addition the pig does have a denser trabecular network compared to humans which might lead to a higher BIC than it would be evident in humans (Mosekilde et al. 1993). Further investigations should address periimplant bone formation on the macroscopic and microscopic level and molecular level in the cortical bone. 


\section{Conclusions}

Our study is the first to evaluate the impact of diabetes on dental implants using a pig model, which is known to have a high degree of similarity with the human organism. We demonstrated that diabetes negatively affects bone mineralization and bone formation in the area surrounding dental implants. These results should be taken into consideration in the clinical setting with patients who have poorly controlled diabetes and an indication for dental implants.

\section{Acknowledgements}

This project was funded by the ELAN-fonds of the University of Erlangen (ELAN-55410013) and the ITI Foundation/Research Committee (ITI-5052007). The work of Andrea Krautheim-Zenk, Susanne Schönherr, and Heidemarie Heider is greatly appreciated. We would also like to thank Elfriede Tissera of the Department of Manufacturing Technology for the electronic scanning pictures. The Authors state that there are no conflicts of interest. 


\section{1}

\section{References}

Adami, S. (2009) Bone health in diabetes: considerations for clinical management. Current Medical Research and Opinion 25, 1057-1072.

Ahmed, N. \& Thornalley, P.J. (2009) Advanced glycation endproducts: what is their relevance to diabetic complications? Diabetes, Obesity and Metabolism 3, 233-245.

American Diabetes Association. (2010) Diagnosis and classification of diabetes mellitus. Diabetes Care 33, 62-69.

Balint, E., Szabo, P., Marshall, C.F. \& Sprague, S.M. (2001) Glucose-induced inhibition of in vitro bone mineralization. Bone 28, 21-28.

Bert, M. (2005) [Etiology of biological complications] In Management der Implantat- Komplikationen, eds Bert, M., Missika, P., Giovannoli, J.L., pp. 227-237. Berlin: Quintessenz.

Boivin, G. \& Meunier, P.J. (2002) The degree of mineralization of bone tissue measured by computerized quantitative contact microradiography. Calcified Tissue International 6, 503-511.

Borden, M., El-Amin, S.F., Attawia, M. \& Laurencin, C.T. (2003) Structural and human cellular assessment of a novel microsphere-based tissue engineered scaffold for bone repair. Biomaterials $\mathbf{2 4}$, 597-609.

Bosetti, M., Zanardi, L., Hench, L. \& Cannas, M. (2003) Type I collagen production by osteoblast-like cells cultured in contact with different bioactive glasses. Journal of Biomedical Materials Research Part A 64, 189-195.

Botolin, S., Faugere, M.C., Malluche, H., Orth, M., Meyer, R. \& McCabe, L.R. (2005) Increased bone adiposity and peroxisomal proliferator-activated receptor-gamma2 expression in type I diabetic mice. Endocrinology 146, 3622-3631.

Brandao-Burch, A., Utting, J.C., Orriss, I.R. \& Arnett, T.R. (2005) Acidosis inhibits bone formation by osteoblasts in vitro by preventing mineralization. Calcified Tissue International 77, 167-174.

Burkhardt, R., Kettner, G., Bohm, W., Schmidmeier, M., Schlag, R., Frisch, B., Mallmann, B., Eisenmenger, W. \& Gilg, T. (1987) Changes in trabecular bone, hematopoiesis and bone marrow vessels in aplastic anemia, primary osteoporosis, and old age: a comparative histomorphometric study. Bone 8, 157-164. 
Buser, D., von Arx, T., ten Bruggenkate, C. \& Weingart, D. (2000) Basic surgical principles with ITI implants. Clinical Oral Implants Research 11, 59-68.

Devlin, H., Garland, H. \& Sloan, P. (1996) Healing of tooth extraction sockets in experimental diabetes mellitus. Journal of Oral and Maxillofacial Surgery 54, 1087-1091.

Donath, K. \& Breuner, G. (1982) A method for the study of undecalcified bones and teeth with attached soft tissues. The Säge-Schliff (sawing and grinding) technique. Journal of Oral Pathology and Medicine 11, 318-326.

Retzepi, M. \& Donos, N. (2010) The effect of diabetes mellitus on osseous healing. Clinical Oral Implants Research 7, 673-681.

Esposito, M., Grusovin, M.G., Coulthard, P., Thomsen, P. \& Worthington, H.V. (2005) A 5-year followup comparative analysis of the efficacy of various osseointegrated dental implant systems: a systematic review of randomized controlled clinical trials. International Journal of Oral \& Maxillofacial Implants 20, 557-568.

Ferreira, S.D., Silva, G.L., Cortelli, J.R., Costa, J.E. \& Costa, F.O. (2006) Prevalence and risk variables for peri-implant disease in Brazilian subjects. Journal of Clinical Periodontology 33, 929-935.

Fiorellini, J.P., Nevins, M.L., Norkin, A., Weber, H.P. \& Karimbux, N.Y. (1999) The effect of insulin therapy on osseointegration in a diabetic rat model. Clinical Oral Implants Research 10, 362-368.

Gerritsen, M., Lutterman, J.A. \& Jansen, J.A. (2000) Wound healing around bone-anchored percutaneous devices in experimental diabetes mellitus. Journal of Biomedical Materials Research 53, 702-709.

Giglio, M.J., Giannunzio, G., Olmedo, D. \& Guglielmotti, M.B. (2009) Histomorphometric study of bone healing around laminar implants in experimental diabetes. Implant Dentistry 9, 143-149.

Gilsanz, V., Roe, T.F., Gibbens, D.T., Schulz, E.E., Carlson, M.E. \& Gonzalez, O. (1988) Effect of sex steroids on peak bone density of growing rabbits. American Journal of Physiology 255, 416-421.

Glowacki, J. (1998) Angiogenesis in fracture repair. Clinical Orthopaedics and Related Research 355, 82-89.

Goodman, W.G. \& Hori, M.T. (1984) Diminished bone formation in experimental diabetes. Relationship to osteoid maturation and mineralization. Diabetes $33,825-831$. 
Jakus, V. \& Rietbrock, N. (2004) Advanced glycation end-products and the progress of diabetic vascular complications. Physiological Research 2, 131-142.

Javed, F. \& Romanos, G.E. (2009) Impact of diabetes mellitus and glycemic control on the osseointegration of dental implants: a systematic literature review. Journal of Periodontology $\mathbf{8 0}, 1719$ 1730.

Kanazawa, I., Yamaguchi, T., Yamamoto, M., Yamauchi, M., Yano, S. \& Sugimoto, T. (2009) Serum osteocalcin/bone-specific alkaline phosphatase ratio is a predictor for the presence of vertebral fractures in men with type 2 diabetes. Calcified Tissue International 85, 228-234.

Kaur, G., Holtfreter, B., Rathmann, W., Schwahn, C., Wallaschofski, H., Schipf, S., Nauck, M. \& Kocher T. (2009) Association between type 1 and type 2 diabetes with periodontal disease and tooth loss. Journal of Clinical Periodontology 9, 765-774.

Kemink, S.A., Hermus, A.R., Swinkels, L.M., Lutterman, J.A. \& Smals, A.G. (2000) Osteopenia in insulin-dependent diabetes mellitus; prevalence and aspects of pathophysiology. Journal of Endocrinological Investigation 23, 295-303.

Kniha, H., Gahlert, M. \& Krekeler, G. (1996) Dental implants--indications and long-term outcome. Fortschritte der Medizin 114, 99-103.

Kotsovilis, S., Karoussis, I.K. \& Fourmousis, I. (2006) A comprehensive and critical review of dental implant placement in diabetic animals and patients. Clinical Oral Implants Research 17, 587-599. 
Kwon, P.T., Rahman, S.S., Kim, D.M., Kopman, J.A., Karimbux, N.Y. \& Fiorellini, J.P. (2005) Maintenance of osseointegration utilizing insulin therapy in a diabetic rat model. Journal of Periodontology 76, 621-626.

Komori, T. (2010) Regulation of bone development and extracellular matrix protein genes by RUNX2. Cell and Tissue Research 339, 189-195.

Laiblin, C. \& Jaeschke, G. (1979) Clinical chemistry examinations of bone and muscle metabolism under stress in the Gottingen miniature pig-an experimental study. Berliner und Münchener Tierärztliche Wochenschrift 92, 124-128.

Lieberman, J.R., Daluiski, A., Einhorn, T.A. (2002) The role of growth factors in the repair of bone. Biology and clinical applications. Journal of Bone and Joint Surgery 84, 1032-1044

Lu, H., Kraut, D., Gerstenfeld, L.C. \& Graves, D.T. (2003) Diabetes interferes with the bone formation by affecting the expression of transcription factors that regulate osteoblast differentiation.

Endocrinology 144, 346-352.

Margonar, R., Sakakura, C.E., Holzhausen, M., Pepato, M.T., Alba, R.C. \& Marcantonio, E. (2003) The influence of diabetes mellitus and insulin therapy on biomechanical retention around dental implants: a study in rabbits. Implant Dentistry 12, 333-339.

Marshall, M., Oberhofer, H. \& Staubesand, J. (1980) Early micro- and macro-angiopathy in the streptozotocin diabetic minipig. Research in Experimental Medicine 177, 145-158.

Martin, A., Komada, M.R. \& Sane, D.C. (2003) Abnormal angiogenesis in diabetes mellitus. Medicinal Research Reviews 23, 117-145.

McCabe, L.R. (2007) Understanding the pathology and mechanisms of type I diabetic bone loss. Journal of Cellular Biochemistry 102, 1343-1357.

Mellado-Valero, A., Ferrer García, J.C., Herrera Ballester, A. \& Labaig Rueda, C. (2007) Effects of diabetes on the osseointegration of dental implants. Medicina Oral , Patología Oral y Cirugía Bucal 12, 38-43.

Mombelli, A. \& Cionca, N. (2006) Systemic diseases affecting osseointegration therapy. Clinical Oral Implants Research 17, 97-103.

Morris, H.F., Ochi, S. \& Winkler, S. (2000) Implant survival in patients with type 2 diabetes: placement to 36 months. Annals of Periodontology 5, 157-165. 
Mosekilde, L., Weisbrode, S.E., Safron, J.A., Stills, H.F., Jankowsky, M.L., Ebert, D.C., Danielsen, C.C., Sogaard, C.H., Franks, A.F., Stevens, M.L., Paddock, C.L. \& Boyce, R.W. (1993) Calciumrestricted ovariectomized Sinclair S-1 minipigs: an animal model of osteopenia and trabecular plate perforation. Bone 14, 379-382.

Moy, P.K., Medina, D., Shetty, V. \& Aghaloo, T.L. (2005) Dental implant failure rates and associated risk factors. International Journal of Oral \& Maxillofacial Implants 20, 569-577.

Neukam, F.W. \& Esser, E. (2000) Implantology. Mund- Kiefer- und Gesichtschirurgie 4, 249-256.

Nevins, M.L., Karimbux, N.Y., Weber, H.P., Giannobile, W.V. \& Fiorellini J.P. (1998) Wound healing around endosseous implants in experimental diabetes. International Journal of Oral \& Maxillofacial Implants 13, 620-629.

Nunamaker, D.M. (1998) Experimental models of fracture repair. Clinical Orthopaedics and Related Research 355, 56-65.

Oates, T.W., Dowell, S., Robinson, M. \& McMahan, C.A. (2009) Glycemic control and implant stabilization in type 2 diabetes mellitus. Journal of Dental Research 4, 367-371.

Pearce, A.I., Richards, R.G., Milz, S., Schneider, E. \& Pearce, S.G. (2007) Animal models for implant biomaterial research in bone: a review. European Cells and Materials Journal 2, 1-10.

Quintero, D.G., Winger, J.N., Khashaba, R. \& Borke, J.L. (2010) Advanced glycation endproducts and rat dental implant osseointegration. Journal of Oral Implantology 2, 97-103.

Saino, H., Luther, F., Carter, D.H., Natali, A.J., Turner, D.L., Shahataheri, S.M. \& Aaron, J.E. (2003) Evidence for an extensive collagen type III proximal domain in the rat femur. II. Expansion with exercise. Bone 32, 660-668.

Schalkwijk, C.G. \& Miyata, T. (2010) Early- and advanced non-enzymatic glycation in diabetic vascular complications: the search for therapeutics. Amino Acids October 20th [Epub ahead of print].

Schlegel, K.A., Lang, F.J., Donath, K., Kulow, J.T. \& Wiltfang, J. (2006) The monocortical critical size bone defect as an alternative experimental model in testing bone substitute materials. Oral Surgery, Oral Medicine, Oral Pathology, Oral Radiology \& Endodontics 102, 7-13.

Schlegel, K.A., Rupprecht, S., Petrovic, L., Honert, C., Srour, S., von Wilmowsky, C., Felszegy, E., Nkenke, E. \& Lutz, R. (2009) Preclinical animal model for de novo bone formation in human maxillary sinus. Oral Surgery, Oral Medicine, Oral Pathology, Oral Radiology \& Endodontics 108, 37-44. 
Siqueira, J.T., Cavalher-Machado, S.C., Arana-Chavez, V.E. \& Sannomiya, P. (2003) Bone formation around titanium implants in the rat tibia: role of insulin. Implant Dentistry 12, 242-251.

Swindle, M.M., Smith, A.C. \& Hepburn, B.J. (1988) Swine as models in experimental surgery. Journal of Investigative Surgery 1, 65-79.

Tawil, G., Younan, R., Azar, P. \& Sleilati, G. (2008) Conventional and advanced implant treatment in the type II diabetic patient: surgical protocol and long-term clinical results. International Journal of Oral \& Maxillofacial Implants 23, 744-752.

Taylor, G.W., Manz, M.C. \& Borgnakke, W.S. (2004) Diabetes, periodontal diseases, dental caries, and tooth loss: a review of the literature. Compendium of Continuing Education in Dentistry 25, 179178.

Thissen, J.P., Pucilowska, J.B. \& Underwood, L.E. (1994) Differential regulation of insulin-like growth factor I (IGF-I) and IGF binding protein-1 messenger ribonucleic acids by amino acid availability and growth hormone in rat hepatocyte primary culture. Endocrinology 134, 1570-1576.

Thorwarth, M., Rupprecht, S., Falk, S., Felszeghy, E., Wiltfang, J. \& Schlegel, K.A. (2005) Expression of bone matrix proteins during de novo bone formation using a bovine collagen and platelet-rich plasma (PRP)—An immunohistochemical analysis. Biomaterials 26, 2575-2584.

Verhaeghe, J., van Herck, E., Visser, W.J., Suiker, A.M., Thomasset, M., Einhorn, T.A., Faierman, E. \& Bouillon, R. (1990) Bone and mineral metabolism in BB rats with long-term diabetes. Decreased bone turnover and osteoporosis. Diabetes 39, 477-482.

von Wilmowsky, C., Stockmann, P., Metzler, P., Harsch, I.A., Amann, K. \& Schlegel, K.A. (2010) Establishment of a streptozotocin-induced diabetic domestic pig model and a systematic evaluation of pathological changes in the hard and soft tissue over a 12-month period. Clinical Oral Implants Research 7, 709-717.

Wild, S., Roglic, G., Green, A., Sicree, R. \& King, H. (2004) Global prevalence of diabetes: estimates for the year 2000 and projections for 2030. Diabetes Care 27, 1047-1053.

World Health Organization. (2006) Definition, Diagnosis and Classification of Diabetes Mellitus and its Complications. Part 1: Diagnosis and Classification of Diabetes Mellitus. Department of Noncommunicable Disease Surveillance, Geneva.

Zayzafoon, M., Stell, C., Irwin, R. \& McCabe, L.R. (2000) Extracellular glucose influences osteoblast differentiation and c-Jun expression. Journal of Cellular Biochemistry 79, 301-310. 
Figure 1: Chronological sequence of the study. $157 \times 30 \mathrm{~mm}(600 \times 600$ DPI $)$ 

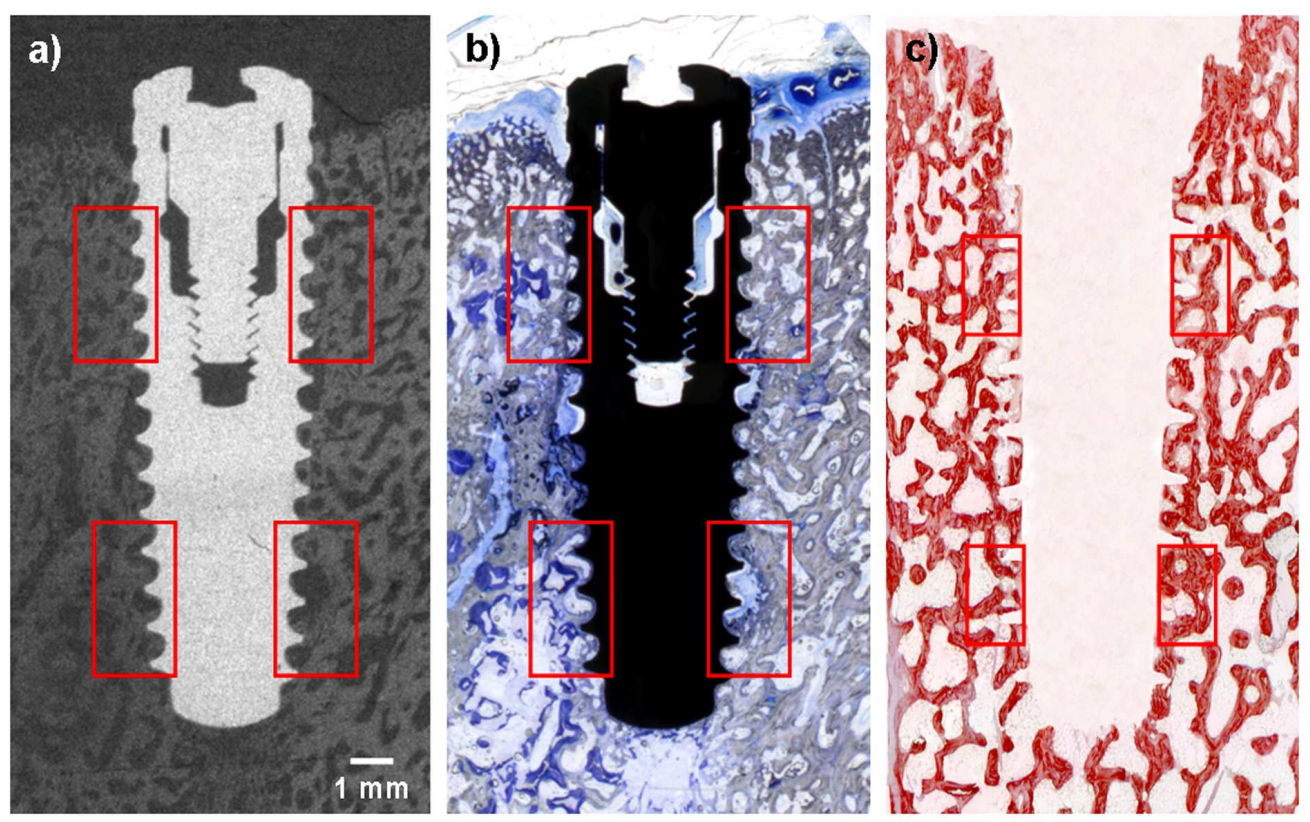

Figure 2: Microradiography (a), histology (b) and immunohistochemically staining (c, collagen typeI staining) of an implant of the diabetic group 12 weeks postoperatively. The figure shows the regions of interested which were used to determine the peri-implant bone mineral density, boneimplant-contact and protein expression using the Bioquant Osteo software V7.10.10. $79 \times 49 \mathrm{~mm}(600 \times 600 \mathrm{DPI})$ 

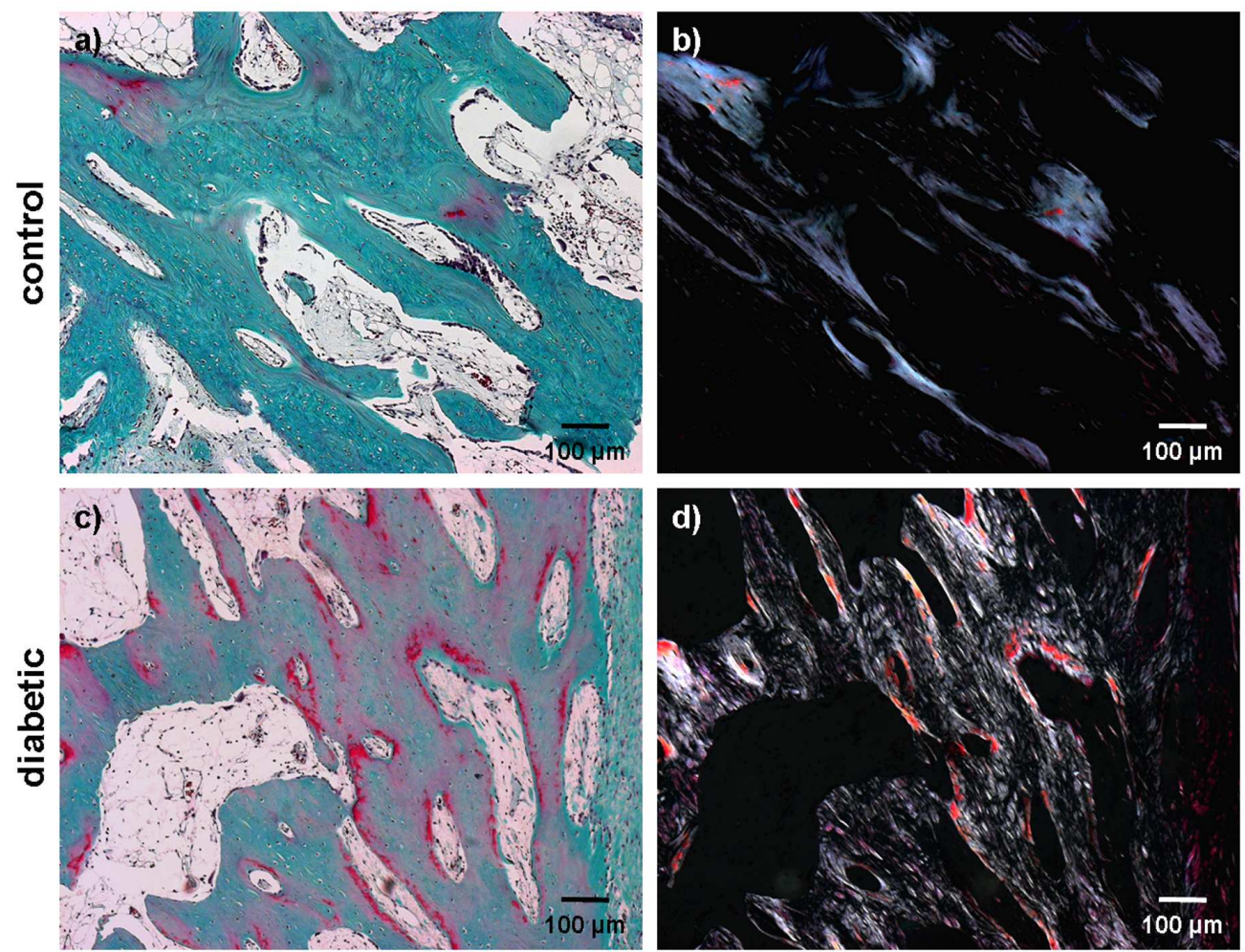

Figure 3: MG staining ( $a$ \& $c$ ) as well as the polarisation microscopy ( $b$ \& d) reveal the qualitative differences of the bone biopsies between the diabetic (c \& d) and the healthy control animals ( $a$ \& b) after 18 months. The bone samples of the diabetic group showed irregularly shaped thicker bone trabecles. The reddish stained mineralization zones were expanded in comparison to the mineralization zones of the healthy controls which was verified by the polarisation microscopy.

$78 \times 59 \mathrm{~mm}(600 \times 600 \mathrm{DPI})$ 

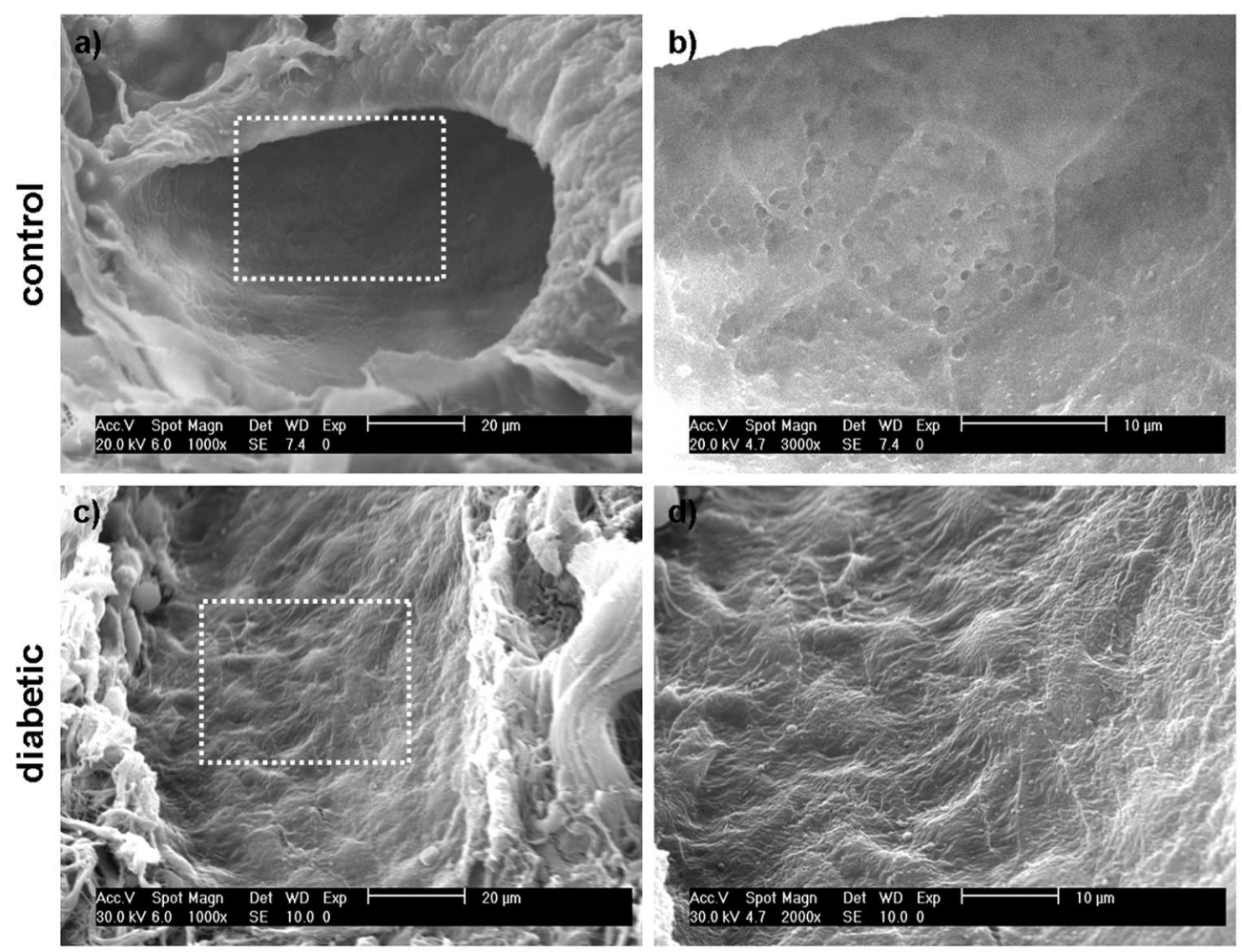

Figure 4: Representative findings of SEM in healthy controls and diabeteic pigs. After 18 months the skin vasculatures of the healthy control animals showed a regularly shaped, smooth endothelium (a $\&$ b). No signs of disconnection of the endothelial cells were visible. On the contrary the skin vasculatures of the diabetic animals showed a distincted altered endothelium with an irregular surface and detached endothelial cells (c \& d). $65 \times 49 \mathrm{~mm}(600 \times 600 \mathrm{DPI})$ 
Figure 5: Measurement of the peri-implant bone mineral density revealed a statistically significant diminished mineral density in the diabetic animals compared to the healthy controls after 4 weeks $(p=0.003)$ as well as after 12 weeks $(p=0.001)$. Bone- Implant contact was negatively affected by the diabetic metabolism and a statistically significant difference between the healthy control group after 4 weeks $(p=0.008)$ as well as after 12 weeks $(p=0.005)$ was present. All values are given as means and standard deviation ( $n$ represents the number of implants investigated). $63 \times 21 \mathrm{~mm}(600 \times 600 \mathrm{DPI})$ 
Figure 6: Collagen type-I protein expression around the implant surface of the control and the diabetic group. Higher collagen protein expression is seen in the diabetic group surface 4 weeks and 12 weeks after implant placement even though no statistically significance could be found. ( $p=$ $0.239, p=0.209)$. Osteocalcin protein expression in the peri-implant bone in the control and in the diabetic group. A lower expression profile is evident in the diabetic group after 4 and 12 weeks with no statistical differences throughout the study $(p=0.661 \& p=0.327)$. All values are given as means and standard deviation ( $\mathrm{n}$ represents the number of implants investigated). $63 \times 21 \mathrm{~mm}(600 \times 600 \mathrm{DPI})$ 


\begin{tabular}{|c|c|c|c|c|c|c|c|}
\hline \multirow[t]{2}{*}{$\begin{array}{c}\text { Time } \\
{[\text { months] }}\end{array}$} & \multicolumn{2}{|c|}{$\begin{array}{l}\text { Blood glucose level } \\
{[\mathrm{mg} / \mathrm{dl}]}\end{array}$} & \multicolumn{2}{|c|}{$\begin{array}{l}\text { Body weight } \\
{[\mathrm{kg}]}\end{array}$} & \multicolumn{2}{|c|}{$\begin{array}{l}\text { IvGTT - Blood glucose level } \\
{[\mathrm{mg} / \mathrm{dl}]}\end{array}$} & \multirow[t]{2}{*}{$\begin{array}{c}\text { Time (IvGTT) } \\
\text { [min] }\end{array}$} \\
\hline & control & diabetic & control & diabetic & control & diabetic & \\
\hline 0 & $70.6 \pm 11.9$ & $68.9 \pm 7.8$ & $33.1 \pm 3.9$ & $32.9 \pm 2.9$ & $99.4 \pm 57.5$ & $283.6 \pm 43.5^{*}$ & prae infusionem \\
\hline 3 & $71.1 \pm 9.8$ & $271.6 \pm 91.1^{*}$ & $58.5 \pm 5.9$ & $45.4 \pm 12.6^{*}$ & $259.2 \pm 71.68$ & $582.6 \pm 38.9 *$ & 10 \\
\hline 6 & $64.8 \pm 6.2$ & $202.6 \pm 50.5^{*}$ & $107.5 \pm 18.3$ & $72.2 \pm 19.8^{*}$ & $175.4 \pm 34.4$ & $527.8 \pm 45.5^{*}$ & 30 \\
\hline 9 & $54.1 \pm 15.8$ & $182.5 \pm 61.3 *$ & $147.8 \pm 16.9$ & $105.4 \pm 23.9^{*}$ & $125.1 \pm 27.2$ & $435.1 \pm 26.3 *$ & 60 \\
\hline 12 & $59.3 \pm 8.5$ & $174.9 \pm 52.1 *$ & $174.3 \pm 14.2$ & $129.1 \pm 29.2^{*}$ & $70.2 \pm 13.7$ & $426.8 \pm 32.8^{*}$ & 120 \\
\hline 15 & $63.7 \pm 11.4$ & $163.8 \pm 48.4^{*}$ & $191.5 \pm 19.7$ & $143.7 \pm 30.6^{*}$ & & & \\
\hline 18 & $61.2 \pm 9.8$ & $146.5 \pm 52.2^{*}$ & $207.3 \pm 17.1$ & $154.4 \pm 41.8^{*}$ & & & \\
\hline
\end{tabular}

Table 1: In this table the blood glucose level and the body weight of the diabetic and healthy control animals are shown over the study period of 18 months. The results of the intravenous glucose tolerance test (IVGTT) are pictured on the right side of the table. These tests were performed four weeks after the induction of the diabetes. The asterix $\left(^{*}\right)$ indicates statistical differences between the diabetic and the healthy control animals $(p<0.05)$. 


\begin{tabular}{|c|c|c|c|c|c|c|c|c|}
\hline $\begin{array}{l}3 \text { Time } \\
\text { [weeks] }\end{array}$ & \multicolumn{2}{|c|}{$\begin{array}{c}\text { BMD } \\
{[\%]}\end{array}$} & \multicolumn{2}{|c|}{$\begin{array}{l}\mathrm{BIC} \\
{[\%]}\end{array}$} & \multicolumn{2}{|c|}{$\begin{array}{c}\text { Collagen type-I } \\
{[\%]}\end{array}$} & \multicolumn{2}{|c|}{$\begin{array}{c}\text { Osteocalcin } \\
{[\%]}\end{array}$} \\
\hline 5 & control & diabetic & control & diabetic & control & diabetic & control & diabetic \\
\hline & $57.59 \pm 7.35$ & $60.08 \pm 10.16^{*}$ & $86.05 \pm 10.15$ & $65.53 \pm 17.98^{*}$ & $25.62 \pm 11.43$ & $29.62 \pm 7.46$ & $16.48 \pm 7.75$ & $14.51 \pm 7.99$ \\
\hline 12 & $46.35 \pm 9.44$ & $44.07 \pm 13.58^{*}$ & $83.95 \pm 14.81$ & $60.95 \pm 17.45^{*}$ & $20.81 \pm 7.07$ & $24.04 \pm 7.57$ & $24.54 \pm 11.06$ & $22.58 \pm 12.41$ \\
\hline
\end{tabular}

